\title{
A ESPIRITUALIDADE: UM RECURSO PEDAGÓGICO NA PRÁTICA DO CUIDADO INFANTIL EM SAÚDE
}

\section{ARTIGO ORIGINAL}

GERONE, Lucas Guilherme Teztlaff de ${ }^{1}$

GERONE, Lucas Guilherme Teztlaff de. A espiritualidade: Um recurso pedagógico na prática do cuidado infantil em saúde. Revista Científica Multidisciplinar Núcleo do Conhecimento. Ano 05, Ed. 09, Vol. 01, pp. 89-107. Setembro de 2020. ISSN: 2448-0959, Link de acesso: https://www.nucleodoconhecimento.com.br/ciencia-dareligiao/cuidado-infantil

\section{RESUMO}

Contexto: Ao longo de toda história humana, é comum encontrar a relação entre educação, saúde e espiritualidade. Atualmente, a discussão sobre a integralidade do ser humano é por reflexão da relação entre a educação, a saúde e a espiritualidade. Objetivos: O presente estudo apresenta uma reflexão sobre a espiritualidade como um recurso pedagógico, especificamente, para uma melhor prática do cuidado infantil entre os profissionais da saúde. Metodológicas: buscou-se um panorama inicial sobre a noção dos termos de estudo e seu histórico, também, realiza-se reflexões que envolvem a espiritualidade como recurso para o cuidado infantil. Para isso, utilizamse referenciais que abordam temas sobre a educação, a saúde e a espiritualidade. Considerações: A espiritualidade como um recurso pedagógico no cuidado infantil possibilita: a) uma reflexão sobre autoconhecimento; b) uma formação disciplinar; c)

${ }^{1}$ Mestre em Teologia pela PUC/PR. Possui Especialização em Comportamento Organizacional; Especialização em Neuropsicopedagogia; Especialização em Filosofia e Sociologia; Especialização em Docência do Ensino Superior. MBAs em Administração e Gestão com ênfase na espiritualidade e religiosidade nas empresas. Graduado em Gestão comercial. Bacharelado em Teologia. Possui Licenciatura em Filosofia e Licenciatura em Pedagogia. 
um desenvolvimento cognitivo e comportamental; d) uma forma terapêutica; e) e uma visão integral e garantia dos direitos e valores humanos.

Palavras-chave: Cuidado, espiritualidade, saúde, profissional, educação.

\section{INTRODUÇÃO}

Na história da humanidade, educação, religião, e saúde estiveram interligadas. É neste contexto que se busca compor uma reflexão sobre a espiritualidade como recurso pedagógico no cuidado infantil entre os profissionais da saúde.

A temática abordada aqui é justificada devido à educação estar ligada a religião e a saúde na construção da visão integral do ser humano. Percebe-se isso, por exemplo, nas práticas dos jesuítas, que ao longo da história que realizam ações integrais através de instituições religiosas, de ensino e da saúde. A segunda justificativa é a significativa contribuição dos métodos pedagógicos para melhor qualidade na prática profissional, por exemplo, na humanização do cuidado. Especialmente neste estudo trata-se da prática do cuidado infantil promovido pelos profissionais da saúde. Para entender melhor, a relação entre religião, saúde e educação, este estudo procura refletir sobre:

a) Noções etimológicas sobre espiritualidade, pedagogia e saúde.

b) Conhecer a relação teórica e prática entre pedagógica e espiritualidade, pedagogia e saúde;

c) Relação entre a pedagogia e os profissionais da saúde;

d) Relação entre espiritualidade e os profissionais da saúde;

e) Por fim, analisar a contribuição da espiritualidade como recurso pedagógico humanizado para prática cuidado de crianças entre os profissionais de saúde. 


\section{NOÇÕES: PEDAGOGIA, ESPIRITUALIDADE SAÚDE}

Conhecer as terminologias torna-se essencial para o entendimento do tema a ser pesquisado, é o inicio mais adequado para o processo de aprendizagem. Sendo assim, aqui serão acunhadas as seguintes noções: pedagogia, espiritualidade e saúde. Também, como um elemento da noção de saúde, será definida a noção do cuidado, especificamente, o cuidado promovido pelos os profissionais da saúde. Ressalta-se que não se trata de terminologias e noções finais, mas, um parâmetro dentro do entendimento acadêmico das áreas da religião, educação e saúde.

Pedagogia: dentro das noções mais acunhadas, pedagogia está inserida no conceito de ensino e educação, na maior parte infantil. Etimologicamente "peda", deriva do grego "paidós", que significa criança, e gogia em grego, significa orientar ou conduzir. Fazendo-se a junção e interpretação primeira, pedagogia, em seu significado é orientar, conduzir a criança (LIBANEO, 2001). De fato, pedagogia pode ser entendida como orientar a criança, ou, denotar um papel de formação dos infantis. Todavia, entre o século XVII e XVIII com grandes avanços sociais, políticos e tecnológicos, a educação é repensada com uma proposta de atualizar os processos pedagógicos, tais como: o entendimento da fase infantil, e a prática do professor (LANZ, 2016). No século XX a educação tem influências positivas de outras áreas do conhecimento que comungam com a visão do ensino e orientação da criança, como por exemplo, o surgimento da psicologia e seus estudos sobre o desenvolvimento e aprendizagem resultaram em uma nova forma de educar e orientar a criança, Dentro deste contexto, passou a se abordar sobre os métodos e recursos pedagógicos de ensino, com isso, surgem também abordagens que ressignificam o sentido da pedagogia. Destaque-se o surgimento da noção da Pedagogia Waldorf, nela, a abordagem pedagógica é pautada na integralidade e no desenvolvimento, físico, espiritual, intelectual e artístico das crianças (LANZ, 2016). Portanto:

Pedagogia é, então, o campo do conhecimento que se ocupa do estudo sistemático da educação - do ato educativo, da prática educativa como componente integrante da atividade humana, como fato da vida social, inerente ao conjunto dos processos sociais. É assim, uma prática humana, uma prática social, que modifica os seres humanos nos seus 
estados físicos, mentais, espirituais, culturais, que dá uma configuração à nossa existência humana individual e grupal (LIBANEO, 2001, p. 6-7).

Essa noção da pedagogia se torna abrangente e permite reflexões e relações com outras importantes dimensões do ser humano. Para Paulo Freire (2005) a pedagogia necessariamente precisa contemplar as experienciais do ser humano, seus valores e morais, construir amizade, conexão, solidariedade, promover sentido e propósito da vida. Estes fatores que permeiam a noção de pedagogia também estão vislumbrados dentro da noção da espiritualidade.

A espiritualidade é uma noção que remete ao estado da natureza do espírito, algo integrado ao ser humano, que impulsiona o ser humano consciente em seus conhecimentos e escolhas vitais, seu conhecimento sobre si e sobre o mundo: seus valores e morais, amizade, conexão, solidariedade, humanismo, bem-estar, sentido e propósito da vida (SOUZA, 2013, p. 97). Neste contexto, a espiritualidade é uma dimensão existencial que se desenvolve a partir das experiências que se desdobra no comportamento religioso, surgido assim, a prática religiosa, ou religiosidade[2]. Neste sentido, religiosidade e espiritualidade estão associadas.

Como noção de saúde entende-se como: o ser humano e sua condição de vida em contexto cultural, princípios e valores com os quais o se relaciona, seus objetivos e experiências, tais como, a amizade, a solidariedade e o sentido de vida, uma situação de completo bem-estar físico, mental e social (LUZ, 2009).

Por fim, dentro do entendimento sobre a prática do cuidado[3] em saúde, Pessini (2002) afirma que é necessário construir a humanização, despertar a solidariedade profissional, empatia e simpatia, um olhar que acende o sentido e confiança do ser humano.

\section{A PEDAGOGIA E A ESPIRITUALIDADE}

A espiritualidade relaciona-se com a pedagogia na reflexão integral do ser humano, nos processos de autoconhecimento, na construção humana e seus valores morais e caminhos da verdade, tais como, a bondade, o amor, a vida, a honestidade, a justiça. 
A espiritualidade também aparece como um exercício de espírito no processo de examinação pedagógica quando educadores buscam encontrar um sentido mais profundo do Ser. Pois, é na interioridade no âmago do espírito, ou seja, um estado puro de consciência, personalidade, pensamento e emoções, que nascem o senso criativo das idéias, as conexões entre os sujeitos e as realidades, as abstrações e concretudes, os pensamentos e as referências de sabedoria, a auto-reflexão sobre hábitos e comportamentos, em que o sujeito passa a conhecer e transformar os limites, fraquezas e medos em aprendizagem e virtudes (GARDNER, 1994).

Como um recurso pedagógico, a espiritualidade compõe a disciplina do ensino religioso. Conforme Boeing, o ensino religioso não se trata apenas de um conceito religioso, mas:

O conhecimento do Fenômeno Religioso, elaborado pelas Ciências da Religião e sistematizado pelo currículo da Educação Básica faz parte da construção cultural da sociedade. Com o Espírito de ressignificar as diferentes dimensões da vida humana. E o Ensino Religioso como componente da formação cidadã torna-se não espaço de releitura e ressignificação do Fenômeno Religioso como também de respeito à pluralidade de cada contexto sociocultural (BOEING, 2009, p. 10-11)

Neste contexto, a espiritualidade é recurso pedagógico para atender as demandas proposta do ensino religioso, pois, ocupa um papel de intermediadora, valoriza a diversidade cultural religiosa e humana, a liberdade religiosa, agrega os valores morais significativos como respeito, amor e caridade. Para Delors a educação religiosa tem:

o propósito de encaminhar o mundo para uma maior compreensão mutua mais sentido de responsabilidade e mais solidariedade, na aceitação de nossas diferenças espirituais e culturais. A educação permitindo o acesso de todos ao conhecimento tem um papel bem concreto a desempenhar no cumprimento desta tarefa universal: ajudar a compreender o mundo e o outro a fim de melhor se compreender (DELORS, 1999, p.50). 


\section{A PEDAGOGIA E SAÚDE}

O desenvolvimento pedagógico está inserido em diversos contextos, tais como, nas relações sociais e familiares, na comunicação, nos movimentos políticos, e na assistência a saúde. Ou seja, é dentro deste contexto amplo, que se insere a atuação do pedagogo. Especialmente na área da saúde, salienta-se o trabalho pedagógico realizado em hospitais ou em ambientes de saúde.

No cenário hospitalar, a atuação do pedagogo é voltada para o atendimento as crianças, jovens, e busca garantir o desenvolvimento afetivo, cognitivo e emocional, assim como, integrar o atendido no contexto escolar. De acordo com Aquino, a atuação do pedagogo no contexto hospitalar pode ser definida em três âmbitos:

agenciar a integração entre a criança, a família, a escola e o hospital, tornando os traumas da internação mais brandos, numa proposta de amenizar a possível desmotivação e estresse ocasionados pela internação; b) propiciar relação e proximidade entre a nova vivência da criança e a do adolescente no hospital com sua rotina diária, anterior ao internamento; e c) possibilitar à criança hospitalizada o acesso à educação, mesmo se encontrando em ambiente hospitalar (AQUINO, SARAIVA, BRAÚNA, 2012, p. 131).

Dentro destes princípios entende que o atendimento do pedagogo ao hospitalizado promove o bem-estar e a integração de recursos pedagógicos, e visa à melhoria do quadro clínico, ajudando o enfermo no enfrentamento do sofrimento causado pela doença. Neste contexto, o pedagogo pode, por exemplo, ministrar aula ou oficina lúdica cognitiva. O objetivo é o desenvolvimento do sistema funcional da linguagem, funções e habilidades, favorecendo a reintegração às atividades cotidianas (AQUINO; SARAIVA; BRAÚNA, 2012).

É importante salientar que a Portaria $\mathrm{n} .{ }^{\circ} 336$ de 19 de fevereiro de 2002 estabelece que o pedagogo faça parte do corpo clínico para atenção psicossocial:

em regime de atendimento intensivo, será composta por: a - 01 (um) médico com formação em saúde mental; b - 01 (um) enfermeiro; c - 03 (três) profissionais de nível superior entre as seguintes categorias 
profissionais: psicólogo, assistente social, terapeuta ocupacional, pedagogo ou outro profissional necessário ao projeto terapêutico.

Sobre o projeto terapêutico que vislumbre um cuidado em saúde e tenha nortes pedagógicos:

Ao analisarmos mais criticamente os mecanismos de produção do cuidado através da construção dos "projetos terapêuticos" e os distintos modelos de atenção à saúde que definem os perfis profissionais competentes para operá-los, podemos abrir novos terrenos para buscar um "novo" tipo de competência profissional no interior das práticas de ensino das escolas, e assim governar os nossos recursos disponíveis e nossos processos pedagógicos de outras maneiras (MERHY, 1999).

Diante disto, o pedagogo é: a) um profissional na área da educação que possui qualidade para conduzir, governar os processos pedagógicos que fazem parte do projeto terapêutico. b) Um profissional qualificado para lidar com questões que envolvem os cuidado em saúde, especialmente, os mentais, como por exemplo, o processo de aprendizagem e cognitivo, e orientação educacional.

Sobre o pedagogo como um promotor terapêutico em saúde:

O campo de atuação do pedagogo que primeiro chama a atenção é o que ele faz com a criança. São as medidas diagnósticas e terapêuticas, os exercícios pedagógicos, as intervenções sugeridas pelo médico escolar e outras. Estas são as chamadas medidas diretas de atuação na educação terapêutica. Um deles é a postura, ou seja, como o educador atua indiretamente no ambiente da criança, como ele pode configurar o ambiente e que efeitos isto tem sobre a criança. O outro é refletir sobre como ele pode atuar de modo educacional-terapêutico sobre a criança, pelo tipo e qualidade de seu encontro e sua relação com a criança (CALLEGARO, 2014, p.118)

Entende-se que a função do pedagogo terapêutico em contexto de saúde é criar um método pedagógico refletindo sobre a atenção, em outras palavras, uma forma de cuidado que considere o ambiente, a realidade, o estado da criança com aquilo que se pretende aprender, uma relação empática de vínculos emocionais. Neste sentido, a função terapêutica do pedagogo é desenvolver ações educativas com olhar amplo e harmonioso, incluindo outras dimensões do paciente, seus interesses, propósitos e sentidos de vida. 
Neste âmbito, o pedagogo "busca construir conhecimentos sobre esse novo contexto de aprendizagem que possam contribuir para o bem estar da criança enferma" (FONTES, 2005, p. 122). Para isso, é necessário o pedagogo considerar algumas dimensões:

A contribuição das atividades pedagógicas para o bem-estar da criança enferma passa por duas vertentes de análise. A primeira aciona o lúdico como canal de comunicação com a criança hospitalizada, procurando fazê-la esquecer, durante alguns instantes, 0 ambiente agressivo no qual se encontra, resgatando sensações da infância vivida anteriormente à entrada no hospital. Essa vertente procura distrair a criança e, muitas vezes, o que consegue é irritá-la, e certamente não contribui para que ela reflita sobre a própria experiência e aprenda com ela. A segunda trabalha, ainda que de forma lúdica, a hospitalização como um campo de conhecimento a ser explorado. Ao conhecer e desmitificar o ambiente hospitalar, ressignificando suas práticas e rotinas como uma das propostas de atendimento pedagógico em hospital, o medo da criança, que paralisa as ações e cria resistência, tende a desaparecer, surgindo, em seu lugar, a intimidade com o espaço e a confiança naqueles que ali atuam (FONTES, 2005, p. 122).

Diante do acima exposto, entende-se que o papel do pedagogo no ambiente hospitalar tem dimensões educacionais que fazem interfaces com a saúde, onde uma acontece na dependência da outra. Promover educação para uma criança hospitalizada não é somente ensinar, mas também, ajudar, auxiliar a trazer saúde e bem estar. Não bastará o pedagogo promover o conhecimento se o hospitalizado não tiver saúde para aprender. No espaço hospitalar é necessário despertar dimensões lúdicas, potencializar a criatividade sobre o conhecimento e autoconhecimento, dar significado existencial ao internado em meio ao seu sofrimento e dor, resgatar a esperança e confiança, criar identidade para estabelecer a humanização no processo pedagógico e no cuidado hospitalar e, transformar os estados físicos, mentais, cognitivos e espirituais.

\section{A PEDAGOGIA NO CONTEXTO DOS PROFISSIONAIS DA SAÚDE}

Em uma pesquisa feita nas grades dos cursos das áreas da saúde: enfermagem, medicina, psicologia, assistência social, fisioterapia e fisioterapia (BRASIL, 1989), 
apenas a enfermagem e a psicologia possuem temas sobre a educação relacionada à prática profissional.

$\mathrm{Na}$ enfermagem estuda-se a educação em saúde com o objetivo integrante da dimensão educativa do perfil profissional do Enfermeiro. O Conteúdo programático aborda: a Relação Educacional e a Sociedade; Concepções pedagógicas, suas finalidades e implicações na Educação brasileira; Processo ensino, aprendizagem, metodologia de ensino; Estruturas curriculares e integração ensino, serviço, comunidade; Elementos da avaliação da aprendizagem, seu papel e implicações; Etapas da prática pedagógica e seus elementos, aplicando em atividades de educação e saúde (BRASIL, 1989). Para Quadros et al. (2019, p. 11):

os benefício do diálogo entre a pedagogia e a enfermagem. Pois a enfermagem apesar de já possuir espaço para se experimentar como educador, tem muito que aperfeiçoar neste fazer; e a pedagogia apesar de já ter sua visão holística de mundo pensando em seus alunos como seres indissociáveis em seus conceitos políticos, sociais, pessoais e culturais ainda deseja adquirir novos saberes sobre as mais diferentes temáticas que surgem em seu cotidiano, dentre elas a saúde.

De acordo com acima exposto, de um lado, a pedagogia contribui para a enfermagem na visão integral-holística do ser humano e sua realidade, do outro lado, a enfermagem pode contribuir para a pedagogia em questões do cuidado, como por exemplo, como pedagogo inserido no ambiente de saúde pode reagir diante das doenças e epidemias através de orientações sobre higiene, primeiros socorros, indícios de quadros de doença e outros.

Na Psicologia se abordada questões da pedagogia:

a) $\mathrm{Na}$ aprendizagem no processo cognitivismo: A psicologia cognitiva procurar entender como o aprendizado apreensão de informações e do conhecimento imediato de um objeto metal (CORREIA, 2001).

b) Na psicologia comportamental e aprendizagem, que é:

uma teoria da aprendizagem baseada na ideia de que todos os comportamentos são adquiridos através do 
condicionamento. Condicionamento ocorre através da interação com o ambiente. Comportamentalistas acreditam que nossas respostas aos estímulos ambientais moldam nossas ações (ALVES, 2019).

c) Na psicanálise e aprendizagem, sendo que:

A Educação e a Psicanálise percorrem um complexo caminho, entrelaçando seus saberes sobre o desenvolvimento do ser humano. Esse entrelaçar permitiu o levantamento de questões relacionadas ao funcionamento psíquico do ser humano, à relação de transferência aluno-professor, ao prazer em aprender (questão do desejo), à terapêutica da Educação, à linguagem etc. Assim, a Psicanálise - como corpo teórico - e a Educação - como discurso social - imbricaram-se em um processo de mudanças que afetou tanto uma quanto outra no que tange suas áreas de atuação (RIBEIRO, 2014, p. 15).

d) No humanismo e aprendizagem que:

Defende que o ensino deve de estar centrado no formando, ou seja, cada pessoa tem o seu próprio percurso e tem maior responsabilidade para decidir o que quer aprender, tornando-o autônomo no seu processo de aprendizagem. O educando tente a descobrir pelo seu próprio caminho, numa atitude de auto-realização e custo-avaliação, num processo de "tornar-se pessoa", sendo esta a chave do processo de aprendizagem (APRENDIZAGEM HUMANISTA, 2019).

e) Na psicologia construtivista e aprendizagem o:

Construtivismo é uma das correntes empenhadas em explicar como a inteligência humana se desenvolve partindo do principio de que o desenvolvimento da inteligência é determinado pelas ações mútuas entre o individuo e o meio. A ideia é que o homem não nasce inteligente, mas também não é passivo sob a influência do meio, isto é, ele responde aos estímulos externos agindo sobre eles para construir e organizar o seu próprio conhecimento de forma cada vez mais elaborada (MENDES, 2019).

Também, existe na grade curricular da Psicologia: a abordagem sobre psicologia e a escola que trata as funções específicas do psicólogo escolar, as competências e habilidades do psicólogo escolar; Visões teóricas da Psicologia Escolar; Instrumentos técnicos para uso do psicólogo na escola; Áreas de intervenção do psicólogo na escola; Áreas de desafio ao Psicólogo Escolar; Possibilidades de reeducação e ações preventivas (BRASIL, 1989). 
Diante do acima exposto pode-se entender que os cursos de enfermagem e psicologia inserem em suas grades curriculares temas da educação-pedagogia para relacionar melhor a prática com a teoria, melhorar auto-avaliação profissional, aplicar métodos de conhecimento dos sujeitos envolvidos na pratica profissional, qualificar a prática profissional, habilitar o profissional para atuar em outros espaços como em escolas e na comunidade em geral , e como uma formação continuada visando à humanização em saúde (LIBANEO, 2001). De acordo com Batista:

formar profissionais para atuar no sistema de saúde sempre foi um desafio. Trazer o campo do real, da prática do dia a dia de profissionais, usuários e gestores mostra-se fundamental para a resolução dos problemas encontrados na assistência à saúde e para a qualificação do cuidado prestado aos sujeitos. A mudança na formação acadêmica de estudantes e professores do campo da saúde também se tem mostrado necessária (BATISTA, 2011, p. 884).

Entende-se que a formação dos profissionais da saúde tem sido uma das pautas centrais para o sucesso do programas em saúde. A formação adquirida por processos pedagógicos aparece como o instrumento mais eficaz para melhorar o trabalho entre os profissionais da saúde e os usuários, como por exemplo, adquirir experiências reais que contribuam para o aprendizado e resolutivas de problemas. Neste contexto, o Ministério da Saúde em 2004 criou a Política Nacional de Educação Permanente em Saúde (PNEPS) como uma estratégia do Sistema Único de Saúde. Trata-se de uma proposta de aprendizagem para o exercício profissional, estabelecendo relação entre o aprender e o ensinar no dia a dia, assim, potencializando e possibilitando as mudanças e transformações na prática dos profissionais da saúde (BRASIL, 2004).

\section{A ESPIRITUALIDADE NO CONTEXTO DOS PROFISSIONAIS DA SAÚDE}

A espiritualidade no contexto dos profissionais da saúde é um fator histórico teórico, por exemplo, o inicio da medicina é caracterizada por dimensões espirituais, como: os mestres curandeiros, a magia e o místico da cura. Sendo isso uma constante em todas as civilizações e épocas (HEIMANN, 2003). 
Na ldade Média e no início da modernidade devido aos avanços dos cursos da área saúde, especificamente na medicina, as universidades da Europa concedem ao aos formados em medicina o titulo de doutor com objetivo de criar uma personalidade profissional, visto que anteriormente os médicos eram vistos como curandeiros, figuras místicas e sacerdotais (LANDMANN, 1984).

Entretanto, para Pitta (1991) apenas no século 19 os profissionais da saúde começam a desenvolver suas práticas profissionais sem relação direta com as práticas espirituais. O advento da Revolução Industrial teve como principio o avanço tecnológico, o que influenciou a medicina prestar um cuidado e serviço em saúde de uma forma técnica (HEIMANN, 2003).

Isto é bom quando a tecnologia proporciona melhor qualidade de vida, todavia, o uso demasiado da tecnologia, mesmo que proporcione positivas melhorias no estado de saúde e doença pode resultar em desamparo de importantes dimensões humanas, tais como: o respeito à dignidade humana, o entendimento sobre a dor, a valorização da comunicação, das crenças religiosas e questões espirituais. É neste contexto que emana entre os profissionais da saúde um propósito em responder as dimensões humanas dos enfermos, entre elas, a espiritual (PERES, 2007).

Em um estudo Gerone (2014) pesquisou sobre como os profissionais da saúde entendem a questão da espiritualidade e a saúde. Os resultados da pesquisa apontam que a espiritualidade ajuda melhorar a qualidade de vida e a saúde. Acredita-se que a espiritualidade não é somente um apoio, mas, um recurso e aspecto importante do cuidado em saúde.

Em momento de dor e sofrimento o paciente recorre à sua espiritualidade como forma de recurso para enfrentar a adversidades causas pela ausência de saúde. Por isso, muitos profissionais da saúde reconhecem a influência positiva da espiritualidade na saúde. A espiritualidade como um fator psíquico e transcendental tem a capacidade de promover resiliência e suporte emocional, despertar questões do âmago da existência e dar sentidos ao sujeito em meio à dor, sofrimento e estresse, e 
proporcionar a presença solidária por meio do amor, do consolo e da esperança (GERONE, 2015).

Diante disto, profissionais da saúde estão integrando ou valorizando a espiritualidade na prática do cuidado como uma forma de promover saúde, pois, mesmo diante da limitação em diagnosticar ou curar uma doença, é possível cuidar do ser humano, vêlo além da enfermidade, um Ser multifacetado com dimensão biopsicosocioespiritual, sentidos e propósitos existências que transcendem seu estado de enfermidade.

\section{A ESPIRITUALIDADE COMO UM RECURSO PEDAGÓGICO NO CUIDADO INFANTIL ENTRE OS PROFISSIONAIS DA SAÚDE}

Especificamente, os profissionais da saúde atuantes no meio infantil necessitam entender que cuidar de uma criança não é a mesma coisa de cuidar de um adulto. $O$ profissional precisa possuir noções pedagógicas para melhor cuidar da criança, como por exemplo, utilizar recursos lúdicos para estimular o tratamento, falar em uma linguagem apropriada com a criança, valorizar dimensões como a empatia, a criatividade, a descoberta e o acolhimento (BARBOSA, 2002). É neste contexto, que se pode integrar a espiritualidade como um recurso pedagógico, pois, a espiritualidade possui em sua essência noções semelhante à da pedagogia. Ao pensar em espiritualidade surgem sentimentos como: a empatia, a criatividade, o acolhimento, o valor humano, o lúdico e o místico. Diante disto, evidencia as convergências e resultados da espiritualidade como recurso pedagógico na prática de cuidado infantil entre os profissionais da saúde:

a) A espiritualidade no cuidado infantil pode ser uma promotora de autoconhecimento. Desenvolve-se a espiritualidade na mesma perspectiva do autoconhecimento, em uma busca intrínseca num espaço subjetivo de procura de identidade, sentidos e propósitos de vida (DANTAS, 2019). Neste cenário, é sabido que o processo de aprendizagem é mais aproveitado quando a criança ao aprender, encontra sentido, propósito existencial. Ou seja, aprender, não se trata transferir ou adquirir conteúdo, mas, encontrar (in)formação que comunguem com a realidade da criança, seus sentidos e propósitos de vida. 
Ainda, aprender é um processo de subjetividade: aprende-se para viver e Ser (ALMEIDA, 2019). Neste contexto, a espiritualidade como promotora do autoconhecimento possibilita dimensões importantes para aprender, tornando-se assim, um recurso pedagógico para a prática do cuidado. Em que o profissional ao integrar a espiritualidade como recurso pedagógico na prática do cuidado possibilita a criança o autoconhecimento: sentidos e propósitos vida, viver e Ser.

b) A espiritualidade como formação de valores morais que assegurem o bem-estar da criança no processo de cuidado. Para Machado (2019) os valores são: a) um conjunto de características pessoais ou sociais que determinam a forma do comportamento. b) talento, reputação, coragem e valentia. Neste sentido, a espiritualidade auxilia o profissional a desenvolver um cuidado infantil que vise à disciplina como um recurso pedagógico para assegurar o bem-estar e valorizar o comportamento que transmite talento e coragem.

c) A espiritualidade pode ser um recurso para um melhor desenvolvimento pedagógico e cuidado em saúde. Destaca-se aqui o coping como um recurso espiritual e educacional para saúde. De acordo Compas (2006) o coping é recurso cognitivo e comportamental utilizado para lidar com situações problemáticas, estresse e sofrimento. O coping pode ser: positivo quando proporcionar resiliência, superação e aceitação. Ou negativo quando causa sentimento de culpa, vergonha, medo, agressão e estresse. Para Takiuti (1997) a fase infantil é uma etapa de muito estresse e turbulências que interfere nos estados emocionais, cognitivos e comportamentais. De acordo com Takiuti (1997) crianças que apresentam o coping negativo possuem problemas de comportamento, como, insegurança, desobediência e agressão. Neste sentido, o profissional pode inserir a espiritualidade no cuidado através do coping positivo e, educar, orientar a criança em sua necessidade cognitivas e emocionais, proporcionando sentimentos positivos, como resiliência em meio aos problemas, coragem, autoestima e outros que são importantes para o tratamento em saúde como também para aprender.

d) A educação terapêutica: é uma junção entre pedagogia e a psicologia. Segundo a Organização Mundial de Saúde, a educação terapêutica é uma forma harmoniosa de 
adquirir, desenvolver, manter competências para gerir a vida em um estado de doença (CALLEGARO, 2014). Para Callegaro (2014) a educação terapêutica possui alguns aspectos, entre eles, o espiritual, que se manifesta através de práticas pedagógicas da linguagem e os gestos.

No contexto como recursos pedagógicos para o cuidado, a linguagem é entendida com uma comunicação empática e construtiva para lidar com a doença. Os gestos são expressões e atitudes que procurem transmitir sentimento harmonioso e criatividade para lidar com doenças. Para Piaget (1978) a criatividade é mais evidente na infância e é um instrumento de mudança, desenvolvimento e evolução.

e) A espiritualidade como promotora da educação integral: a noção de educação integral é uma visão multidimensional que integra fenômenos, cognitivos, emocionais, psicológicos, sociais, culturais e espirituais. A educação integral é garantida na Constituição de 1988 - Estatuto da Criança e do Adolescente, Lei № 8.069/1990 (ECA); Lei de Diretrizes e Bases da Educação Nacional, Lei oo 9.394/1996 (LDB); Plano Nacional de Educação, Lei 10.172/2001 (PNE, 2001-2010). Ou seja, a educação integral é uma visão plena e de promoção dos valores do ser humano, entre elas, a dimensão espiritual, um direito garantido em Lei (CAMARGO, 2019).

Neste sentido, a espiritualidade como aspecto da educação integral é cultivadora dos valores humanos. No contexto o cuidado infantil, torna-se um recurso pedagógico ao garantir o direito a uma educação integral respeitando e construindo os valores humanos, a solidariedade e o respeito, a consciência do Ser, e de pertencer e transcender (CAMARGO, 2019).

\section{CONSIDERAÇÕES FINAIS}

Considera-se que tema é oportuno, pois lida relaciona importantes dimensões do ser humano, espiritualidade, educação e saúde. Conforme visto, tais dimensões estão relacionadas etimologicamente. Os sentidos das palavras: saúde, espiritualidade e pedagogia, estão relacionadas tanto no quesito teórico como prático. Por isso, como visto ao longo deste trabalho é cabível a reflexão da temática aqui abordada, que 
trouxe uma reflexão interdisciplinar entre áreas da saúde, educação e religião. Considera-se que no desenvolvimento deste trabalho, percebeu que não há como falar de educação sem espiritualidade e saúde, e vice e versa.

Conforme visto neste estudo, destaca-se que a enfermagem e a psicologia incluem na grade curricular questões sobre a espiritualidade e educação. Isso tem possibilitado novas formas de cuidar, orientar, ensinar.

Considera-se que no contexto em saúde, espiritualidade é um recurso indispensável para o pedagogo, especialmente para aquele que atuam em hospitais. A espiritualidade aparece como promotora de saúde e educação, e consegue dar significado e propósitos que transcendem o estado de doença. Ou seja, não se limita a saúde e o ensino em uma condição, mas, na produção de autoconhecimento e aprendizado.

Considera-se que especificamente que os profissionais atuantes no meio infantil necessitam entender e possuir noções pedagógicas. Consideram-se alguns recursos pedagógicos indispensáveis para profissional da saúde promover no cuidado a criança:

a) Utilizar recursos lúdicos para estimular o tratamento.

b) Falar em uma linguagem apropriada com a criança.

c) Valorizar dimensões como a empatia, a criatividade, descoberta e acolhimento.

Considera-se que é nestes pontos que existe convergência para espiritualidade ser um recurso pedagógico para cuidado infantil:

a) na reflexão sobre autoconhecimento;

b) na formação disciplinar;

c) no desenvolvimento cognitivo e comportamental; 
d) em forma terapêutica;

e) na visão integral e garantia dos direitos e valores humanos.

Por fim, percebe-se a necessidade de novos estudos que aprofundem uma reflexão sobre a espiritualidade como recurso pedagógico na prática do docente e aprendizagem; sobre a espiritualidade como promotora de conhecimento e autoconhecimento no processo de ensino e aprendizagem; sobre a espiritualidade como manifesto de uma educação integral e humanista; sobre a espiritualidade como uma disciplina na formação de alunos e docentes.

\section{REFERÊNCIAS}

APRENDIZAGEM HUMANISTA. Teoria da aprendizagem. Disponível em: http://aprendizagemhumanista.weebly.com/teorias-da-aprendizagem.html. Acesso em 16 de Nov de 2019.

ALMEIDA, P. DE; MITJÁNS MARTíNEZ , A. (2019). A Configuração Subjetiva da Ação do Aprender. Revista Obutchénie, 3(1), 88-113. Disponível em: https://doi.org/10.14393/OBv3n1.a2019-50592. Acesso em 14 de Nov de 2019.

ALVES, C. O que é Behaviorismo e Psicologia Comportamental? Disponível em: https://opas.org.br/o-que-e-behaviorismo-e-psicologia-comportamental/ Acesso em 16 de Nov de 2019.

AQUINO, S. L. de; SARAIVA, A. C. L. C.; BRAÚNA, R. de C. de A. Representações sociais da atuação do pedagogo na saúde: saberes envolvidos e experiências compartilhadas. Interfaces da Educação, Paranaíba, MS, v. 3, n. 7, p. 128-145, 2012. Disponível em: . Acesso em: 25 jan. 2014.

BARBOSA, ECV. O vivenciar da equipe de enfermagem com os familiares de crianças internadas em UTI pediátrica [dissertação]. Rio de Janeiro: Faculdade de Enfermagem da Universidade do Estado do Rio de Janeiro; 2002. 
BARBOSA, Maria Aparecida. Lexicologia, Lexicografia, Terminologia, Terminografia, Identidade científica, Objeto, Métodos, Campos de atuação. SIMPÓSIO LATINOAMERICANO DE TERMINOLOGIA E I ENCONTRO BRASILEIRO DE TERMINOLOGIA TÉCNICO-CIENTíFICA. 2., 1990, Brasília, Anais... p. 152-158.

BATISTA, Karina Barros Calife; GONCALVES, Otília Simões Janeiro. Formação dos profissionais de saúde para o SUS: significado e cuidado. Saude soc. São Paulo, v. 20, n. 4, p. 884-899, Dec. 2011.

BOEING, Antônio. Ensino Religioso enraizado nas Ciências da Religião. Dialogo Revista do Ensino Religioso. №55, agosto/setembro, 2009.

BRASIL, Ministério da Saúde. Portaria n.ำ 198/GM/MS, de 13 de Fevereiro de 2004. Institui a Política Nacional de Educação Permanente em Saúde como estratégia do SUS para a formação e o desenvolvimento de trabalhadores para o setor e dá outras providências. Brasília, Ministério da Saúde, 2004.

BRASIL. Lei de Diretrizes e Bases da Educação Nacional. Lei número 9394, 20 de dezembro de 1996.

BRASIL. MINISTÉRIO DA SAÚDE. Capacitação Pedagógica para Instrutor / Super-visor - Área de Saúde.1989.

CAMARGO, T. Educação integral e espiritualidade: os benefícios desta relação para a formação integral do ser humano. Disponível em: https://www.lume.ufrgs.br/bitstream/handle/10183/117566/000966595.pdf?sequence $=1$ \&isAllowed $=\mathrm{y}$. Acesso em 14 de Nov de 2019.

CARVALHO, Gilson. A saúde pública no Brasil. Estud. Av. São Paulo, v. 27, n. 78, p. 7-26, 2013.

CORREIA, Mônica F. B.; LIMA, Anna Paula Brito; ARAUJO, Claudia Roberta de. As Contribuições da Psicologia Cognitiva e a Atuação do Psicólogo no Contexto Escolar. Psicol. Reflex. Crit., Porto Alegre , v. 14, n. 3, p. 553-561, 2001 
Available from <http://www.scielo.br/scielo.php?script=sci_arttext\&pid=S0102$79722001000300010 \&$ Ing=en\&nrm=iso>. access

on 16 Nov. 2019. http://dx.doi.org/10.1590/S0102-79722001000300010.

COLLEGARO, B. Arte Médica Ampliada Vol. 34 | N. 3 | Julho / Agosto/ Setembro de 2014.

COMPAS, Bruce E. Psychobiological processes of stress and coping: implications for resilience in children and adolescents. Comments on the papers of Romeo \& McEwen and Fisher et al. Annals of the New York Academy of Sciences, v. 1094, p. 226-234, 2006.

CURY, Carlos Roberto Jamil. Direito à educação: direito à igualdade, direito à diferença. Cad. Pesqui. São Paulo, n. 116, p. 245-262, julho de 2002.

DANTAS, Gabriela Cabral da Silva. "Autoconhecimento"; Brasil Escola. Disponível em: https://brasilescola.uol.com.br/psicologia/autoconhecimento.htm. Acesso em 11 de novembro de 2019

DELORS, Jacques. Educação: um tesouro a descobrir. Relatório para a UNESCO da Comissão Internacional sobre Educação para o século XXI. 10 Ed. São Paulo: Cortez; 2006.

DUBUC, Robert. Manuel Pratique de Terminologie. Quebec, Linguatech, 1985.

FONTES, Rejane de S.. A escuta pedagógica à criança hospitalizada: discutindo o papel da educação no hospital. Rev. Bras. Educ., Rio de Janeiro, n. 29, p. 119138, Aug. 2005

FREIRE, P. Pedagogia do Oprimido. 49 ed. Rio de Janeiro: Paz e Terra, 2005.

GARDNER, HOWARD. Estruturas da mente: a teoria das inteligências múltiplas. Porto Alegre: Artes Médicas, 1994. 
GERONE, Lucas Guilherme Teztlaff de. Um olhar sobre a Religiosidade/Espiritualidade na Prática do Cuidado entre profissionais de saúde e pasto ralistas. Dissertação (Mestrado em Teologia). Disponível em: /www.biblioteca.pucpr.br/tede/tde_busca/arquivo.php?codArquivo=. Acesso em 12 de Nov de 2019.

JUNQUEIRA, Sérgio Rogério Azevedo. Formação Docente. Diálogo - Revista do Ensino Religioso $\mathbf{n}^{\circ} 45$ - Fevereiro/2007.

LANZ, R. A Pedagogia Waldorf - Caminho para um Ensino Mais Humano. São Paulo, Brasil: Ed. Antroposófica. 2016.

LIBANEO, José Carlos. Pedagogia e pedagogos: inquietações e buscas. Educ. rev. Curitiba, n. 17, p. 153-176, junho de 2001.

LOBO, Ney. Filosofia espírita da Educação. Vol. 1 a 5. Rio de Janeiro, FEB, 1990.

MACHADO, J. Valores: a principal disciplina da vida. Disponível em: https://jcconcursos.uol.com.br/noticia/empregos/valores-humanos-disciplina-da-vida4603. Acesso em 12 de Nov de 2019.

MATTOS, Luiz Alves de. Primórdios da educação no Brasil: o período heróico (1549-1570). Rio de Janeiro: Aurora, 1958.

MERHY, Emerson Elias. Apostando em Projetos Terapêuticos Cuidadores: desafios para a mudança da escola médica ou utilizando-se da produção dos projetos terapêuticos em saúde como dispositivo de transformação das práticas de ensinoaprendizagem que definem os perfis profissionais dos médicos. Campinas; 1999.

MENDES, S. A Aprendizagem no Construtivismo. Disponível em: http://www.profala.com/artpsico85.htm. Acesso em 16 de Nov de 2019.

MIRANDA, K.C.L.; BARROSO, M.G.T. A contribuição de Paulo Freire à pratica e educação crítica em enfermagem. Rev. Latino - Am. Enfermagem, Ribeirão Preto, v.12 (4), p.631-635, 2004. 
PAIVA, J. Espiritualidade e qualidade de vida: Pesquisas em psicologia. Porto Alegre: EDIPUCRS, 2004.

PESSINI, L. (2002). Humanização da dor e sofrimento humano no contexto hospitalar. Bioética, Brasília, Conselho Federal de Medicina, 10(2). Disponível em: <http://www. cfm.org.br>. Acesso em 24 de Junho de 2019.

PIAGET, J. O nascimento da inteligência na Criança. Rio de Janeiro: Zahar Editores, $1978,3^{\circ}$ edição.

PUCHALSKI, C. M. "Espiritualidade e medicina: os currículos na educação médica". Journal of Education Câncer: 0 Jornal Oficial da Associação Americana para a Educação do Câncer, 21 (1), pp. 14-18, 2006.

QUADRO, V; et al. Enfermagem E Pedagogia: A Junção Entre 0 Cuidado E A Educação - Um Relato De Experiência. Disponível em: https://propesp.furg.br/anaismpu/cd2009/ensino/317-274-1-SM.pdf. Acesso em 16 de Nov de 2019.

RIBEIRO, Márden de Pádua. Contribuição da psicanálise para a educação: a transferência na relação professor/aluno. Psicol. educ., São Paulo, n. 39, p. 2330, dez. 2014 em $<$ http://pepsic.bvsalud.org/scielo.php?script=sci_arttext\&pid=S141469752014000200003\&lng=pt\&nrm=iso >. acessos em 16 nov. 2019

SENA, R.R.; LEITE, J.C.A.; SILVA, K.L.; COSTA, F.M. Projeto Uni: cenário de aprender, pensar e construir a interdisciplinaridade na prática pedagógica da enfermagem. Interface (Botucatu), Botucatu, v.7(13), p. 79-90, 2003.

SEGRE, Marco; FERRAZ, Flávio Carvalho. O conceito de saúde. Rev. Saúde Pública, São Paulo , v. 31, n. 5, p. 538-542, Oct. 1997. Available from $<$ http://www.scielo.br/scielo.php?script=sci_arttext\&pid=S0034-

$89101997000600016 \&$ lng $=$ en\&nrm=iso $>$. access

on 15 Nov. 2019. http://dx.doi.org/10.1590/S0034-89101997000600016. 
TAKIUTI, A. D. A saúde da mulher adolescente - 1993. In: MADEIRA F. R. (Org.). Quem mandou nascer mulher? Estudos sobre crianças e adolescentes pobres no Brasil. Rio de Janeiro: Record, 1997. p. 213-290.

YUS, R. Educação Integral uma educação holística para o século XXI. Trad. Daisy Vaz de Moraes. Porto Alegre: Artmed, 2002.

\section{APÊNDICE - REFERÊNCIAS DE NOTA DE RODAPÉ}

2. Uma qualidade daquilo que faz parte da religião, entendida a partir de sua etimologia latina, religare, que significa "religação" entre o homem e Deus (DERRIDA, 2000, p. 52)

3. Entendido como tratamento em saúde, acompanhamento em saúde, promoção da saúde.

Enviado: Agosto, 2020.

Aprovado: Setembro, 2020. 